\title{
Level of physiological, anatomical and pathological knowledge of the singing voice on the part of professional and amateur singers
}

Daniel Rodríguez Marconi ${ }^{(1)}$ Camilo Morales Cárdenas ${ }^{(1)}$

Liliana Gaete Antilen ${ }^{(1)}$

Marta Garrido Ormeño(1)

Camila Pardo Reyes ${ }^{(1)}$

Facultad de Ciencias de la Salud, Universidad Católica de Temuco, Temuco, Chile.

Conflict of interests: Nonexistent

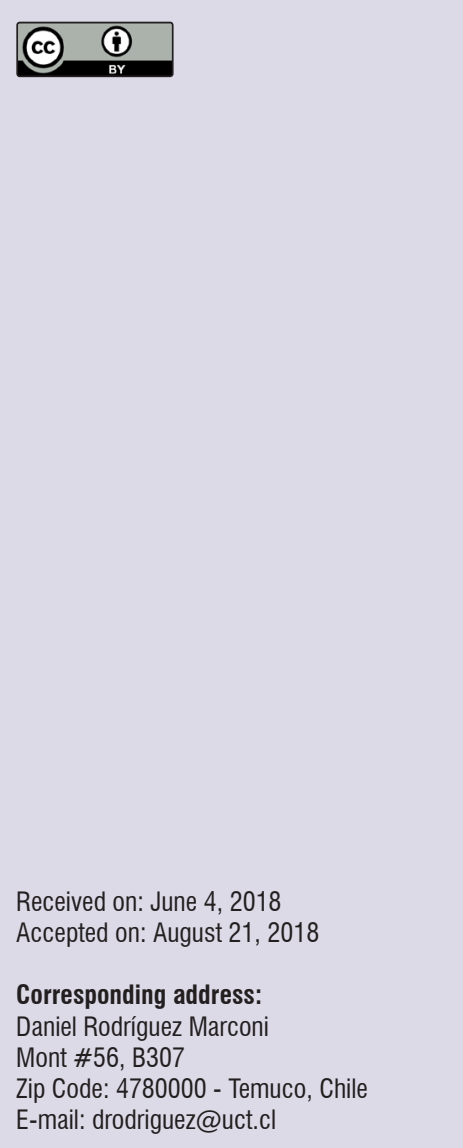

\section{ABSTRACT}

Purpose: the knowledge concerning care of the voice on the part of professional and amateur singers in Chile is relevant for voice professionals and also for speech pathologists who work in disorder prevention and voice care. It is important to know if there are differences between both groups regarding the knowledge of voice care.

Methods: the "Vocal Awareness Questionnaire for Singers" was applied to a sample of 66 singers: 33 professional and 33 amateur singers. Three areas of knowledge were evaluated: anatomy and physiology of the larynx, vocal hygiene and voice pathologies.

Results: there were no significant differences in the knowledge of voice care between professional and amateur singers both at a general level and in specific areas of knowledge. The topic of vocal hygiene obtained the highest percentage of correct answers in both groups, while the lowest percentage was in the area of voice pathologies.

Conclusions: there were no differences in the level of knowledge on voice care between the professional and amateur singers included in this study. In both groups, the level of knowledge was from low to moderate. This could increase the incidence of vocal pathologies in both groups.

Keywords: Voice; Singing; Voice Quality; Voice Disorders 


\section{INTRODUCTION}

The correct use of the phonation mechanism is important,on the long term, for artists who use their voice as the chosen instrument of their musical career ${ }^{1}$. For this reason, all professional or amateur singers should be familiar with the basic processes involved in voice production. According to Alessandroni et al. ${ }^{2}$, singers lacking a detailed knowledge of the structure of the vocal folds and their principal characteristics, or of the nervous, sensory and motor processes involved in the phonation process, are unable to detect certain problems in their own voice or that of others. A singer ${ }^{3}$ or singing teacher ${ }^{4}$ possessing a good understanding of the physiology of the vocal cords can more easily visualize their operation and be aware of the basic physiological processes involved. Unfortunately, voice difficulties are common among both voice teachers and singers, even more so than among the general population ${ }^{5}$.

For singers, this knowledge is relevant, because not all voices possessing good esthetic characteristics are healthy voices. Singers lacking adequate knowledge of good vocal techniques are at greater riskof losing their vocal efficiency in the long term ${ }^{3}$. As a result, both singing teachers and singers may be affected by dysphonia, not to mention the fact that certain organic pathologies are caused by untreated muscle tension dysphonia ${ }^{3}$.

Not all singers are equally knowledgeable about vocal hygiene and care, or about specific aspects such as laryngeal physiology, vocal techniques, orthe pathologies that may affect the voice of singers ${ }^{6}$. According to Behlau, professional singers are more knowledgeable about the physiology of the vocal apparatus and the processes involved in voice production, as well as good habits of vocal hygiene, as a result of their formal professional education, including their vocal techniques. On the contrary, popular singers are flexible individuals, whose training is often informal or intuitive, they rehearse withoutperforming vocal warm up exercises or applied techniques and havea lower level ofknowledge, as they lack formal training ${ }^{8}$.

Limited experience on the part of the singer also seems to be a factor conducive toignorance of basic care of the voice. Coelho ${ }^{9}$ and Rosa et al. ${ }^{10}$ say that one of the characteristics commonly found among amateur choir members is their lack of knowledge and their limited experience in comparison with professionals. These problems may be related to thelack of familiarity, on the part of amateur singers, with specific singing techniques ${ }^{10,11}$.

Rosa et $\mathrm{al}^{10} \mathrm{conclude}$ that, at present, the only source of knowledge available to amateur choir members, are the rehearsals provided by their teachers. Techniques such asbreathing exercises, muscular relaxation, vocalizations, andscales fortonal extensionare still commonly used bychoir teachers. However,singers have very limited knowledge ofprocesses taking place at the physiological level andof the effects of the above exercises on voice production ${ }^{12}$.

According to Estabillo ${ }^{13}$, vocal abuse and misusemay take placerepeatedly as a result of habits that are harmfulforsingers' health, and of which they are occasionally aware ${ }^{14}$, such as excessive screaming, forced vocalizations, speaking in excess, performing hard glottal attack, inhalation of dust and harmful gases, or badvocal and practice techniques that create hyperfunction of the vocal folds. As a result of vocal misuse and abuse, many singers suffer from chronic laryngitis, vocal nodules, vocal polyps, contact ulcers and/or laryngeal queratosis ${ }^{13}$.

Singers' goodvocal habits and hygieneare alsorelevant forpreventingpathologies.According to Dassie et al. ${ }^{11}$, both lyrical and pop singers have bad habitsforvocal health, such as smoking and drinking, althoughthere aredifferences betweenlyrical and pop singers, aslyrical singerspossess greaterknowledge of vocalperformance and the role of voice therapists.

Knowledge of the physiology of the larynx, of care of the voice and of vocal misuse and abuse are important for the care of the singer's voice. However, these are aspects that have not been addressed in Chile till now. The objective of this study was to evaluate the level of knowledgeabout care of the voice in a sample of Chilean professional and amateur singers by applying the questionnaireVocal Awareness Questionnaire for Singers.

\section{METHODS}

This researchwas approved by the Ethics Committee ofUniversidad CatólicadeTemuco.

This study is based on the positivist paradigm. It is a non-experimental, descriptive and cross-sectional study ${ }^{15}$.

The variables considered were the following: gender, age, the items used inthe questionnaire "Vocal awareness questionnaire for Singers" (Annex 1), and the categories of professional / amateur singer. 


\section{Sample}

The study considered asample of 66 singers: 33 professional singers and 33 amateur singers in the cities of Temuco and Santiago of Chile. The samplewas selected by convenience sampling. As group distribution criterion, we followed the one suggested byGrape et al. ${ }^{16}$ : A Professional Singer[PS] is a singer who has followed formal professional education, includingvocal techniques, with regular classes and rehearsals, andwho receives remuneration for their singing. An Amateur Singers[AS] is a singer who takes singing lessons for non-professional reasons, during their spare time, and receives no remuneration for singing.

We excluded thosesingers that have followed studies and/or specialties invocology, for examplephono-audiologists orear, nose, and throat specialists.

\section{Instrument}

Vocal Awareness Questionnaire for Singers: we adapted tothe Spanishlanguage Colleen Braun-Janzen \& L. Zeine's questionnaire ${ }^{6}$. The original instrument has 6 items,only threeof which were used in this study: anatomical-physiological knowledge (PART Vl; questions 39 to 45, PART VII 56), vocal hygiene (PART $V$; questions 29 to 38) and pathologies of the singing voice (PART VI; questions 46 to 55,PART VII,57 to 59). The other 3 items were not used as they are not pertinent to this research.

\section{Procedure}

Singers were recruited either in person or throughemail. After the study objectives had been explained, including the risks and benefits of the study, each singer signed an informed consent form. Next, each participantcompleted the questionnaireVocal Awareness questionnaire for singers in one of the following manners: in person or online (Google Forms). Each participant was given 15 minutes to complete the questionnaire.

The Chi-squared was used to determine the differences between groups. The variables were subjected to descriptive and inferential analysis, considering a statistical significance value of $<0.05$.

\section{RESULTS}

The analysis of the data is presented in Tables 1 and 2 . 
Table 1. Baseline data on professional and amateur singers

\begin{tabular}{|c|c|c|c|}
\hline & & \multicolumn{2}{|c|}{ Type of singer } \\
\hline & & PS & AS \\
\hline \multirow{2}{*}{ Gender } & Females & $19(57.6 \%)$ & $19(57.6 \%)$ \\
\hline & Males & $14(42.4 \%)$ & $14(42.4 \%)$ \\
\hline \multirow{9}{*}{ Type ofmusic education } & None & $5(15.2 \%)$ & $17(51.5 \%)$ \\
\hline & Some, but no degree was completed & $7(21.2 \%)$ & $14(42.4 \%)$ \\
\hline & Undergraduate music degree & $11(33.3 \%)$ & $2(6.1 \%)$ \\
\hline & Masters & $5(15.2 \%)$ & $0(0.0 \%)$ \\
\hline & Doctorate & $1(3.0 \%)$ & $0(0.0 \%)$ \\
\hline & Vocal technique & $1(3.0 \%)$ & $0(0.0 \%)$ \\
\hline & Degree in lyrical singing & $1(3.0 \%)$ & $0(0.0 \%)$ \\
\hline & Music composition & $1(3.0 \%)$ & $0(0.0 \%)$ \\
\hline & Singing performer & $1(3.0 \%)$ & $0(0.0 \%)$ \\
\hline \multirow{7}{*}{ (Vocal) diagnosis } & No pathologies & $27(81.8 \%)$ & $30(90.9 \%)$ \\
\hline & Vocal nodules & $4(12.1 \%)$ & $1(3.0 \%)$ \\
\hline & Contact ulcers & $0(0.0 \%)$ & $0(0.0 \%)$ \\
\hline & Gastroesophageal reflux & $1(3.0 \%)$ & $0(0.0 \%)$ \\
\hline & Reinke's edema & $0(0.0 \%)$ & $0(0.0 \%)$ \\
\hline & Vocal fold paralysis & $1(3.0 \%)$ & $0(0.0 \%)$ \\
\hline & Functional dysphonia & $0(0.0 \%)$ & $2(6.1 \%)$ \\
\hline \multirow{6}{*}{$\begin{array}{c}\text { Have you ever being } \\
\text { given speech therapy } \\
\text { services? }\end{array}$} & None & $19(57.6 \%)$ & $29(87.9 \%)$ \\
\hline & Voice therapy & $8(24.2 \%)$ & $2(6.1 \%)$ \\
\hline & Articulation & $1(3.0 \%)$ & $1(3.0 \%)$ \\
\hline & Other & $4(12.1 \%)$ & $0(0.0 \%)$ \\
\hline & No treatment received & $0(0.0 \%)$ & $0(0.0 \%)$ \\
\hline & Control & $1(3.0 \%)$ & $1(3.0 \%)$ \\
\hline
\end{tabular}

PS = Professional singers;AS = Amateur singers

Table 2. Baseline data on professional and amateur singers

\begin{tabular}{ccc}
\hline & \multicolumn{2}{c}{ Type of singer } \\
\cline { 2 - 3 } & PS & AS \\
\cline { 2 - 3 } & Average \pm S.D. & Average \pm S.D. \\
\hline Age of the singer & $37.09 \pm 14.83$ & $29.96 \pm 14.31$ \\
Years of individual singing training & $7.6 \pm 10.14$ & $1.72 \pm 2.0$ \\
Years as a choir director & $5.12 \pm 7.51$ & $2.6 \pm 5.55$ \\
Years as a singing teacher & $5.15 \pm 8.46$ & $0.81 \pm 2.17$ \\
Singing hours per week & $10.45 \pm 9.13$ & $7.17 \pm 6.18$ \\
Years singing in a choir & $8.66 \pm 8.45$ & $11.95 \pm 14.1$ \\
\hline
\end{tabular}

S.D. $=$ Standard Deviation; $P S=$ Professional singers; $A S=$ Amateur singers 


\section{General knowledge}

In general terms, considering both groups, $33.8 \%$ of the singers evidenced limited knowledge (0-32\%correct answers), $49.4 \%$ evidenced moderateknowledge
(33-65\% correct answers) and $17.1 \%$ evidenced high level of knowledge (66-100\% correct answers).

\section{Knowledge per item}

Table 3. Level of knowledge on laryngeal anatomy and physiology, vocal hygiene and vocal pathology per group

\begin{tabular}{|c|c|c|c|c|c|}
\hline Level of knowledge & \multirow{2}{*}{ Group } & Limited & Moderate & High & \multirow{2}{*}{$P$ value } \\
\hline Variable & & $\%(n)$ & $\%(n)$ & $\%(n)$ & \\
\hline \multirow{2}{*}{$\begin{array}{c}\text { Knowledge of anatomy and } \\
\text { physiology }\end{array}$} & PS & $24.20 \%(8)$ & $72.80 \%(24)$ & $3.00 \%(1)$ & \multirow{2}{*}{0.18} \\
\hline & AS & $39.4 \%(13)$ & $51.60 \%(17)$ & $9.10 \%(3)$ & \\
\hline \multirow{2}{*}{ Knowledge of vocal hygiene } & PS & $0.00 \%(0)$ & $45.40 \%(15)$ & $54.60 \%(18)$ & \multirow{2}{*}{0.23} \\
\hline & AS & $3.00 \%(1)$ & $60.60 \%(20)$ & $36.40 \%(12)$ & \\
\hline \multirow{2}{*}{$\begin{array}{l}\text { Knowledge of vocal } \\
\text { pathologies }\end{array}$} & PS & $60.60 \%(20)$ & $39.40 \%(13)$ & $0.00 \%(0)$ & \multirow{2}{*}{0.19} \\
\hline & AS & $75.80 \%(25)$ & $24.20 \%(8)$ & $0.00 \%(0)$ & \\
\hline
\end{tabular}

PS =Professional singers; $A S=$ Amateur singers; *Statistical significancefor Chi-square test

There were nodifferencesbetween groups in terms of the items related to anatomical-physiological knowledge $(p=0.18)$, vocal hygiene $(p=0.23)$ and knowledge ofvocal pathology $(p=0.19)$ (Table 3$)$.

The questions that received the greatest percentage of correct answers included the following: function of the diaphragm $(71.2 \%)$, the relaxation function of yawning $(77.3 \%)$, the knowledge of treatment forlaryngitis $(96.9 \%)$, the damage caused bythroat-clearing (93.9\%), the damage caused by speaking in noisy environments (89.3\%) and theprogression of vocal nodules (56.1\%).

The questionswith the highestpercentage of incorrect answers or lack of knowledge are related to the glottis $(75.8 \%)$, the function of the cricothyroid muscle (90.9\%), the use of the stomach for breathing (59.1\%), the function of the soft palate $(75.8 \%)$, the effects of antihistamines on the voice (50\%), the harmful effects of whispering (63.6\%) and the effects of speaking in a low tone $(77.3 \%)$. The itemreceiving the highestpercentages of incorrect answers or lack of knowledge was the one related to vocal pathologies. The singers had no knowledge of the physiopathology ofvocal nodules, its etiology per gender $(87.9 \%)$, its bilateral presentation $(71.2 \%)$, the structural characteristics of the nodules $(51.5 \%)$, their progression and evolution (84.9\%), the symptoms associated withvocal nodules (42.4\%) and their treatment (39.4). Similarly, singers gave high percentages of incorrect answersinrelation to the effects ofreflux (63.7\%), contact ulcers (83.3\%) and polyps (72.8\%).

\section{DISCUSSION}

Professional singers are those who have had formal education or training, and have been subjected over several years to the discipline that is characteristic oftheir profession and their vocal techniques, including regular classes and rehearsals. Behlau ${ }^{7}$ states that this group has deeper knowledge of the physiology of the vocal apparatus, of different aspects of voiceproduction, and of habits of vocal hygiene. On the contrary, pop singers are flexible individuals, whose training is intuitive or informal, and they rehearse withoutvocal warm-up exercises or applied techniques ${ }^{7}$. However, ourresults are similar to those of Kwak et al. ${ }^{16}$, which indicate that singers with more advanced studies do not possess significantly greater knowledge of the anatomy of the voice and its physiology. In spite of their relatively low level of knowledge, professional singers recognized that possessing knowledge of the anatomy and physiology of the singing voiceis a pre-requisite for achieving good performance inlyrical singing. This is in agreement with Sielska et al. ${ }^{17}$, who concluded that, for singers, this knowledge is essential forimproving their singing performance.

Both groups gave a high percentage of correct answers in vocal hygiene. In this regard, the type of health care sought by singers may determine their interest in the quality of the voice.Astudy conducted 
by Petty ${ }^{18}$ on professional singers seeking information on vocal health, concludes that singers are more likely to seek information from singing teachers about vocal problems, compared to persons who are not singers, as the latter are more likely to seek advice from doctorsorvoice therapists. The study also indicates that younger singers are more likely to use home remedies in comparison with older singers ${ }^{18}$. Behlau ${ }^{7}$ states that amateur and pop singers are more likely to see a speech therapist for general guidance and for vocal hygiene, due to their high rates of vocal misuse and abuse. In the present study, amateur singers were less likely to visit a speech therapist, with dysphonia being the most frequent motive for the visit. Professional singers are more likely to visit a phono-audiologist, with the main motive being voice therapy. According to a study of music students conducted by Kwak et al. ${ }^{16}$, the more-experienced singers do not possess significantly greater knowledge of the anatomy of the voice and its physiology, but they are more interested invisiting anear, nose, and throat specialist, and in learning about vocal pathologies.

Pazo et al. ${ }^{19}$ say that, of all singers, lyrical singers are the most likely to avoid vocal abuse and misuse, and their vocal technique is more effective in comparison with pop singers, who neglect good vocal technique. Similarly, Achey et al. ${ }^{20}$ state that vocal warm-up exercises are more frequently practiced by opera singers than by pop singers. However, in the present research no marked differences were found in terms of knowledge of vocal techniques, as both groups reportedmoderate to high levels of care of the voice.

The most common pathologies in singers arelaryngitis, vocal nodules and edema. Singers are more likely to perceivevoice symptoms, due to years of selfobservation and the importance accorded to these symptoms bysingers. According to García-López et al. ${ }^{21}$ singers are more likely to sufferpathologies of the singing voice. Theresearchcarried out by BraunJansen $^{6}$ indicates that most singers obtain low scores in knowledge about pathologies. This is confirmed in the present study. Similarly, in the item relative to pathologies of the singing voice there is no significant difference between PS and AS in terms ofknowledge of vocal pathology

It is interesting to note that $82.8 \%$ of the singers in this study evidenced limited or moderate knowledge. Therefore, it can be stated that ahigh percentage of singers requires improvement and education in these areas of knowledge, as indicated by
Broaddus-Lawrence et al. ${ }^{22}$ These researchers state thatthe singers in their study reported obtaining a high degree of benefits and learnings aftertaking classes and practice sessions in vocal hygiene.

We may mention the following limitations of the present study: the relatively small sample size and the limited control over the online filling of the questionnaire. Therefore, these results should be taken withcaution, and not generalized. It is relevant to mention that one third $(33.85 \%)$ of the respondents said they do not know what the role of the phono-audiologistis in relation to singing. Although these datawere not analyzed quantitatively, we consider it advisable to conduct further research in this field within the Chilean context.

\section{CONCLUSION}

Both professional and amateur singers possess limited to moderate general knowledge in terms of anatomy, physiology and pathology of the singing voice. There were no differences detected between these two groups.

The results of this research indicate that the singers in this study do not possess adequate knowledge about the care of the voice. This is the case even for singers who consider themselves professionals. It seems important that singers be educated in the prevention of vocal pathologies.

It seems advisable for new research to be conducted along these lines, based on different classification and exclusion criteria for professional singers, so as to make it possible toanalyze the differences between singers who have followed formal university-level studies and those who have received informal training.

\section{REFERENCES}

1. Donahue EN, Leborgne WD, Brehm SB, Weinrich BD. Reported vocal habits of first-year undergraduate musical theater majors in a preprofessional training program: a 10-year retrospective study. J Voice. 2014;28(3):316-23.

2. Alessandroni N, Etcheverry E. Dirección coral y técnica vocal, ¿un diálogo posible? Reflexiones metodológicas para un trabajo vocal eficiente. ERAS Eur Rev Artist Stud. 2011;3(2):1-11.

3. Pitman MJ. Singer's dysphonia: etiology, treatment, and team management. Music Med An Interdiscip J. 2010;2(2):95-103.

4. Stein $\mathrm{H}$. El arte de cantar: su dimensión cultural y pedagógica. Rev Music Chil. 2000;54(194):41-8. 
5. Tobar LN, Pérez MC, Camacho J. Patología benigna de laringe en docentes y cantantes Benign diseases of larynx in teachers and singers. Acta Otorrinolaringol Cirugía Cabeza y Cuello. 2010;39(1):15-23.

6. Braun-Janzen C, Zeine L. Singers' interest and knowledge levels of vocal function and dysfunction: survey findings. J Voice. 2009;23(4):470-83.

7. Behlau M. Voz: o livro do especialista. Rio de Janiro: Revinter; 2005.

8. Oliveira IB. A educação vocal nos meios de comunicação e arte: a voz cantada. In: Ferreira LP, Oliveira IB, Quinteiro EA, Morato EM (eds). Voz profissional: o profissional da voz. Carapicuíba: Pró-Fono; 1995. p. 33-43.

9. De Castro Coelho A, Daroz IF, Cristina K, Silvério A, Brasolotto AG. Amateur choir singers: self-image, difficulties and symptoms of the singing voice. Rev. CEFAC. 2013;15(2):436-43.

10. Rosa M, Behlau M. Mapping of vocal risk in amateur choir. J Voice. 2017;31(1):118.e1-118.e11.

11. Prestes T, Pereira EC, Bail DI, Dassie-Leite AP. Desvantagem vocal em cantores de igreja. Rev. CEFAC. 2012;14(5):901-9.

12. McHenry M, Johnson J, Foshea B. The effect of specific versus combined warm-up strategies on the voice. J Voice. 2009;23(5):572-6.

13. Estavillo Morante de MDC. La voz: recurso para la educación, rehabilitación y terapia en el ser humano. Rev Interuniv Form del Profr. 2001;9(42):66-75.

14. Boominathan $P$, Rajendran $A$, Nagarajan $R$, Seethapathy J, Gnanasekar M. Vocal abuse and vocal hygiene practices among different level professional voice users in India: a survey. Asia Pacific J Speech, Lang Hear. 2008;11(1):47-53.
15. Salant $P$, Dillman DA. How to conduct your own survey. New York: Willey; 1994.

16. Kwak PE, Stasney CR, Hathway J, Minard CG, Ongkasuwan J. Knowledge, experience, and anxieties of young classical singers in training. $J$ Voice. 2014;28(2):191-5.

17. Sielska-Badurek E, Osuch-Wójcikiewicz E, Sobol M, Kazanecka E, Niemczyk K. Singers' vocal function knowledge levels, sensorimotor self-awareness of vocal tract, and impact of functional voice rehabilitation on the vocal function knowledge and self-awareness of vocal tract. J Voice. 2017;31(1):122.e17-122.e24.

18. Petty BE. Health information-seeking behaviors among classically trained singers. $\mathrm{J}$ Voice. 2012;26(3):330-5.

19. Pazo T, Peña AS, Thompson AL. Realidades y desafíos de la educación vocal en profesionales de la voz en Cuba [Internet]. 2006. Available from: http://www.sld.cu/galerias/pdf/ sitios/rehabilitacion-logo/realidades_y_desafios_ de_la_educacion_vocal_en_profesionales_de_la_ voz_en_cuba.pdf

20. Achey MA, He MZ, Akst LM. Vocal hygiene habits and vocal handicap among conservatory students of classical singing. J Voice. 2016;30(2):192-7.

21. García-López I, Gavilán Bouzas J. The singing voice. Acta Otorrinolaringologica (English Edition). 2010;61 (6):441-51.

22. Broaddus-Lawrence PL, Treole K, McCabe RB, Allen $R L$, Toppin $L$. The effects of preventive vocal hygiene education on the vocal hygiene habits and perceptual vocal characteristics of training singers. J Voice. 2000;14(1):58-71. 


\section{Annex 1. QUESTIONNAIRE - SINGERS' VOCAL AWARENESS \\ Colleen Braun-Janzen, M.Mus.}

INSTRUCTIONS: Please answer allquestions. Unless otherwise indicated, provide one answer per question.

\section{PART I}

1. Age:

2. Gender: $M$

3. Type of voice: Soprano_ Contralto_ Tenor_Baritone _

4. Occupation:

5. Education: Highest level attained (High School degree, University degree, etc.)

6 . What education have you received? (Indicate highest level attained)

1. None

2._Some, but no degree was completed.

3. Undergraduate music degree

4. Masters

5. Doctorate

7. How many years of individual singing training? $\mathrm{N} / \mathrm{A}$

8. How many years as choir director? $\mathrm{N} / \mathrm{A}$

9. How many years as a singing teacher? $\mathrm{N} / \mathrm{A}$

10. On average, how many hours do you sing, per week?

11. How many years singing in a choir?

12. Have you worked as a professional singer (for remuneration)?

1. Yes 2. No

13. Have you ever been diagnosed with a vocal disorder?

1. Yes 2. No

If yes, what was the diagnosis? (tick all that apply)

1. Vocal nodules

2. Contact ulcers

3. Other.

Please provide more information:
4. $\mathrm{N} / \mathrm{A}$

14. a. Have you ever received the services of avoice and speech professional (Speech Therapist)?

1. Yes 2. No

b. If yes, what was the motive? (Tick all that apply)

1. Voice therapy

2. Articulation

3. Other (please specify):

4. N/A

15. What type of professional has given you the most valuable advice on vocal care? (Tick one)

1.___ Singing teacher

2. Choir director

3. School or university courses

4._Speech Therapist

5. __ Other (please specify): 


\section{PART II}

In your opinion, a speech-language pathologistshould be qualified to:

16. Reduce stress in a person's neck area (larynx).

I don't know Yes No

17. Diagnose vocal folds lesions.

I don't know Yes No

18. Help a person raise or lower the tone frequency of their voice.

I don't know Yes No

19. Raise awareness of vocal care.

I don't know Yes No

\section{PART III}

Please indicate your level of knowledge of the following (tick one per area):

1. Limited or no knowledge 2. Basic understanding 3. Complete understanding

20. Anatomy and physiology (function) of voice production 1 .

21. Care of the vocal mechanism 1.

2. 2.

22. Role of the speech therapistv1.

23. Vocal disorders related to abuse of the voice 1 .
2. 3

3.

2.

3.

\section{PART IV}

Are you interested in deepening your knowledge of the following? (Tick).

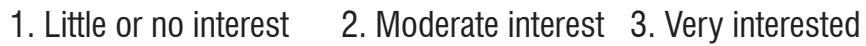

24. Anatomy and physiology (function) of the voice 1 .

25. Role of the speech therapist 1 . 2.

26. Hygiene of vocal apparatus 1.

27. Optimum use of the spoken voice 1 . 2. 3.

28. Vocal disorders 1 . 2. 2.

3. 2. 3. 3.

PART V. (In Parts V, VI and VII, code words are included for the benefit of readers) In your opinion,are the following activities, substances and environmental factors harmful for the voice?

\begin{tabular}{|l|l|l|}
\hline Habits & \multicolumn{1}{c|}{ Yes } & No \\
\hline 29. Speaking when suffering from laryngitis & & \\
\hline 30. Taking antihistamines (for example, Sudafed) & & \\
\hline 31. Throat-clearing & & \\
\hline 32. Prolonged production of /m/ & & \\
\hline 33. Air conditioning & & \\
\hline 34. Drinking coffee & & \\
\hline 35. Whispering & & \\
\hline 36. Speaking in noisy environments & & \\
\hline 37. Yawning & & \\
\hline 38. Speaking in a low tone of voice & & \\
\hline
\end{tabular}




\section{PART VI}

True or False (tick one per question)
1. I don't know
2. True
3. False

39. The principal muscle involved in inhalation is the diaphragm.

I don't know $\mathrm{T}$ $\mathrm{F}$

40.Yawning lowers the throat (larynx) and relaxes the muscles around it (pharyngeal constrictors).
I don't know $\mathrm{T}$
41. The glottis is a cartilage in the larynx.

I don't know $T$

42. The cricothyroid muscle opens the vocal cords.
I don't know $T$ $\mathrm{F}$
43.Falsetto singing requiresstretching of the vocal cords.

I don't know $T \quad F$

44. In diaphragmatic respiration, the stomach is filled with air duringinhalation.

I don't know $T$

45.The soft palate is raised when making nasal sounds during singing ( $\mathrm{n}, \mathrm{m}$, and $\mathrm{ng}$ )

I don't know $T$

46. Vocal nodulesare more frequent in females.
I don't know $T$ $F$
47. Vocal nodules are often present in only one vocal cord

I don't know $T$ $\mathrm{F}$

48. Vocal nodules are small fibrous lumps usually located in the center of the vocal cord.

I don't know $T$ $\mathrm{F}$

49.Vocal nodules, if untreated, may lead to laryngeal cancer.

I don't know $T$

50. If you havechronic heartburn (Gastroesophageal reflux), you should sleep with your legs slightly raised I don't know $\mathrm{T}$ $\mathrm{F}$

51. Contact ulcersare associated with high intensity of the voice

I don't know $T$ $\mathrm{F}$

52. Vocal nodules generally appear gradually

I don't know $\mathrm{T}$

53. Polyps in the vocal cordsmay appear suddenly, after a single episode of vocal abuse.

I don't know $T$

54. Contact ulcers are more frequent in males.

I don't know $T$ $\mathrm{F}$

55. Chronic heartburn (Gastroesophageal reflux) put you at risk of developing contact ulcers in the vocal cords.

I don't know $\mathrm{T}$ $\mathrm{F}$

PART VII. Multiple selection

56. Physiological measurements indicate that a "Support" for singing (with optimum projection and resonance) is closely associated with:

1.

2. expansion of the rib cage I don't know

3. _ r reduction of the larynx and stronger closing of the vocal cords.

4. r reduction of the membrane duringinhalation, and compression ofthe abdomenduringexhaling.

57. What are the symptoms reported bysingers with small / incipient nodules?

1. I don't know

2. Pain, hoarseness, limited tonal range

3. H__ Hoarseness, difficulty in singing register transitions (vocal passages), and difficulties in fortissimo singing 
4. Difficulties withlow intensity singing (piano), slight noises when breathing /noises when starting and difficulties during vocal passages.

5. Pain, difficulties with low-intensity singing (piano), and hoarseness.

58. The best treatment for the first stages ofvocal nodules is:

1. I don't know

2. Surgical removal

3. Total resting of the voice until symptoms disappear

4._ Voice therapy focused on change vocal habits

5._Whispering till vocal folds return to normal

59. The best treatment for the first stages of laryngitis is:

1. I don't know.

2. Cortisone

3. ___ Total resting of the voice until symptoms disappear

4.___ Voice therapy focused on change vocal habits

5. W__ Whispering till vocal folds return to normal

\section{PART VIII}

60. When you have phlegm / mucus in the throat, you should (tick all that apply).

a. Cough or clear the throat

b. Swallow

c. Drink water

d. Dr_ Dry cough (no secretion, "choppy" coughing)

61. When you have a hoarse voice, you should (tick all that apply).

a. Increase the intake of liquids

b. Stop singing, or sing only for important occasions

c. Avoid alcohol

d. U__ Use a vaporizer or humidifier at night

e. ___ Sing as usual

f. ___ Decrease the use of thevoice for speaking

g. ___ Cancel all social activities that involve speaking

h. Whisper when communicating

i. S__ Sleep longer

j. Avoid caffeine

k. Avoid smoky environments

l. ____ Avoid speaking in noisy environments

m.___ Take cortisone if you have to use your voice

n. ___ Take antihistamines (for example, Loratadine or chlorphenamine)

\section{PART IX}

62. The following statements reflect a singer's attitude to singing. Please choose the one that most closely describes your feelings:

1. singing is the most important thing in my life

2. Singingis one of the 3 most important thingsin my life.

3.____ singingis one of the 5 most important thingsin my life.

4. ___ singingis one of the 10 most important thingsin my life.

5. ___ singingis not one of the 10 most important thingsin my life. 